\title{
Cement-fly ash mortars durability, with fly ash from fluidized bed boilers and conventional combustion, exposed to aggressive environment influence
}

\author{
Elżbieta Janowska-Renkas", Jolanta Kowalska, Grzegorz Janus, and Agnieszka Kaliciak \\ Opole University of Technology, Civil Engineering and Architecture Faculty, ul. Katowicka 48, \\ 45-061 Opole, Poland
}

\begin{abstract}
The study shows results of research on the aggressive environment impact $(1,3$ and $5 \% \mathrm{HCl}$ solution) on durability of cement mortars with fraction from 30 to $45 \%$ by mass of fly ashes from the fluidized bed combustion (FBC fly ash) and conventional fly ashes used separately and in the form of a mixture. The impact of aggressive environments on durability of cement and ash mortars was tested for aperiod of 365 days, by testing the compressive strength, linear changes, mass loss and porosity. It was demonstrated that mortars with the content of FBC fly ashes, after 365 days of tests showed the higher resistance to aggressive environment impact. It is confirmed by e.g. their higher compressive strength, and thus the reduced total porosity. Reduction of total porosity content $(<50 \mathrm{~nm})$ was accompanied by the increased compressive strength, which in the aqueous environment was in favour of cement mortars, and in the aggressive environment in favour of cement and ash mortars. It was demonstrated that the content of pores $<200 \mathrm{~nm}$ was lower for mortars with FBC fly ashes and mixtures of ashes regardless of environment the mortars were stored in. A beneficial impact of FBC fly ashes was found on physical properties of mortars, i.e. reduction of the shrinkage, lower mass loss and reduced destruction of mortars in the acid corrosion environment. That effect was especially beneficial for the mortar with higher ( $45 \%$ by mass) content of FBC fly ashes, regardless of aggressive character of the environment.
\end{abstract}

\section{Introduction}

Production of electricity in Poland is mainly based on coal (81\%). Power Plants and Combined Heat and Power Plants use hard coal and lignite as the conventional source of energy generation [1]. Restrictions imposed by the European Union in a form of Energy and Climatic Package, a so-called "3x20" of December 2008, forced changes on the domestic energy market referring among others to reduction of carbon dioxide emission, increase of power generating plants capacity and increase the contribution of the renewable energy sources in the total energy production [2].

*Corresponding author: e.janowska_renkas@interia.eu 
A poor technical condition of coal-fired power plants and combined heat and power plants is a great threat to environment and economy of our country [2]. A solution for these issues appeared to be the retrofit of coal combustion method and gasification of fuels [3]. Combustion of fuels in fluidized bed boilers introduced in recent years, contributed to reduction of $\mathrm{SO}_{2}$ and $\mathrm{NO}_{\mathrm{x}}$ emission to atmosphere, with simultaneous use of low-quality fuels [3]. Furthermore, nearly all power plants and combined heat and power plants co-fire biomass to reduce $\mathrm{CO}_{2}$ emission, but its percentage is still low.

One type of waste obtained during fuel combustion in fluidized bed boilers are fly ashes, which depending on sorbents used in the furnace, have different properties, which result from their variable composition. Reduction of the combustion temperature in this type of boilers to ca. $850^{\circ} \mathrm{C}$, has an influence on obtaining fly ashes with a different composition and properties than ashes produced with the conventional method. The chemical composition of ashes from fluidized bed combustion contain oxides of such elements like: silicon, aluminium, iron, calcium, magnesium, sodium, potassium, titanium or manganese. Main phases of fly ashes are dehydrated minerals that form a waste rock if a primeval character, unreacted sorbent $\left(\mathrm{CaCO}_{3}\right)$, free $\mathrm{CaO}$ and anhydrite. The low temperature of fuels combustion in fluidized bed boilers $\left(800-900^{\circ} \mathrm{C}\right)$ causes that no liquid phase occurs in the bed, as well as no mullite and of glazed, round forms of ash grains. Therefore FBC fly ashes are different from conventional ones, e.g. in structure - irregular shape, phase composition and higher fineness, i.e. larger specific surface area [4-10]. In addition, fly ashes from fluidized bed boilers, despite pozzolanic properties, also show hydraulic properties [6-13]. Calcium sulphate contained in FBC ashes originating from a flue gas desulphurization process, causes that FBC ashes may be used directly to the clinker, without an additional time controller for cement binding process [13].

Due to physical and chemical properties mentioned above, the FBC fly ashes have become an interesting material for their use in the mortar and concrete production technology. However, standards currently in force do not allow to apply FBC fly ashes in the cement, due to high loss on ignition values in these ashes and alarming high calcium sulphate $\left(\mathrm{CaSO}_{4}\right)$ content, which may be a reason of the delayed ettringite formation and thus destruction of the cement matrix of mortars and cement. [9, 14-20].

A negative impact on mortars durability may be caused by a shrinkage associated with their change in volume. The presence of shrinkage may result e.g. from the high quantity of cement paste, a high water to cement ratio, a high $\mathrm{C}_{3} \mathrm{~A}$ content or composition of pastes [17-19]. Uncontrolled shrinkage has the influence on reduction of mortar tightness, which may lead to easier access of water and aggressive substances inside the mortars, which in consequence may be a reason for their faster destruction.

Striving to increase durability of binder based products forces constant search for better and better solutions in production technologies of these materials. Obtaining cement-based materials, with low permeability, especially within the interfacial transition zone, where a higher content of calcium hydroxide $\mathrm{Ca}(\mathrm{OH})_{2}$ occurs, determines their higher strength to aggressive ions impact. Durability of hydratation products, including C-S-H phase, is especially threatened by the acid corrosion [4, 9, 18]. In addition, in result of the decalcification on the mortar hardened surface, a substance is formed with a gel consistency [17-18].

Mortars, and thus cements, which are highly alkaline materials, with the $\mathrm{pH}$ value reaching 12-13, due to increased reactivity, easy react with all aggressive substances with the acid reaction. All water/solutions with $\mathrm{pH}<6$ are deemed aggressive and hazardous for mortars and concretes. The main source of acid aggressive media may be: underground water $\left(\mathrm{H}_{2} \mathrm{SO}_{4}\right.$ ), peat bogs (aggressive $\mathrm{CO}_{2}$ and humic acid), municipal wastewater (biogenic $\left.\mathrm{H}_{2} \mathrm{SO}_{4}\right)$, acid rains $\left(\mathrm{H}_{2} \mathrm{SO}_{4}\right.$ and $\left.\mathrm{HNO}_{3}\right)$, gases present in air, i.e.: $\mathrm{CO}_{2}, \mathrm{SO}_{3} \mathrm{i} \mathrm{NO}_{\mathrm{x}}$ and waste 
water from agricultural production containing organic acids: acetic acid, lactic acid and formic acid [13].

The study included research and testing, in order to determine properties and possibilities to apply materials of cement and ash mortars (FBC fly ashes and conventional ashes) in conditions exposed to corrosion impact with a low $\mathrm{pH}$ value.

\section{Test materials and methods}

Mortars were made based on Portland cement CEM I 42,5 R with and without content of fly ashes: from fluidized bed combustion and conventional. The chemical composition and the specific surface area acc. to Blain of the cement and fly ashes are given in Table 1. Standard sand was used to mortars in accordance with requirements of PN-EN 196-1:2016-07 [21].

Table 1. Chemical composition of CEM I cement, fly ashes from fluidized bed combustion and fly ashes from conventional boilers

\begin{tabular}{|c|c|c|c|}
\hline Constituent & $\begin{array}{c}\text { Cement } \\
\text { CEM I 42,5 R }\end{array}$ & $\begin{array}{c}\text { FBC fly ashes } \\
\text { Pf }\end{array}$ & $\begin{array}{c}\text { Conventional fly } \\
\text { ashes } \\
\text { PI }\end{array}$ \\
\hline Loss on ignition & 2.57 & 4.30 & 1.81 \\
\hline Insoluble matter & 0.46 & - & - \\
\hline $\mathrm{SiO}_{2}$ & 19.79 & 39.26 & 40.20 \\
\hline $\mathrm{Fe}_{2} \mathrm{O}_{3}$ & 2.98 & 3.79 & 2.00 \\
\hline $\mathrm{Al}_{2} \mathrm{O}_{3}$ & 5.76 & 29.37 & 6.00 \\
\hline $\mathrm{CaO}$ & 62.28 & 12.04 & 43.20 \\
\hline $\mathrm{MgO}$ & 1.71 & 1.79 & 4.70 \\
\hline $\mathrm{SO}$ & 2.62 & 3.13 & 0.10 \\
\hline $\mathrm{K}_{2} \mathrm{O}$ & - & 1.01 & - \\
\hline $\mathrm{Na}_{2} \mathrm{O}$ & 0.75 & 1.49 & - \\
\hline $\begin{array}{c}\mathrm{Specific} \mathrm{surface} \\
\text { area acc. to Blaine } \\
\text { [cm } / \mathrm{g} \text { ] }\end{array}$ & 4000 & 8300 & 3800 \\
\hline
\end{tabular}

Mortars were prepared while maintaining the constant consistency determined by a cone penetrometer test method. Composition of mortars based on Portland cement CEM I 42,5R, with and without content of fly ashes from fluidized bed combustion and conventional ashes is given in Table 2 . The following symbols were adopted in the study: CEM I- cement type CEM I 42,5R, $\mathrm{P}_{\mathrm{f}}$ - fly ashes from fluidized bed combustion, $\mathrm{P}_{1}$ - fly ashes from conventional boilers.

Table 2. Composition of mortars tested

\begin{tabular}{|c|c|c|c|c|c|}
\hline Type of mortar & $\begin{array}{c}\text { CEM I 42,5 R } \\
\text { [g] }\end{array}$ & $\begin{array}{c}\text { Pf } \\
{[\mathbf{g}]}\end{array}$ & $\begin{array}{c}\text { PI } \\
{[\mathbf{g}]}\end{array}$ & $\begin{array}{c}\text { Water } \\
{[\mathbf{g}]}\end{array}$ & $\mathbf{w} / \mathbf{b}$ \\
\hline ZI (100\% CEM I 42,5 R) & 450 & - & - & 216 & 0.48 \\
\hline ZII (CEM I + 30\% Pf) & 346 & 104 & - & 255 & 0.57 \\
\hline ZIII (CEM I + 45\% Pf) & 310 & 140 & - & 276 & 0.61 \\
\hline ZIV (CEM I + 25\% Pf + 20\% Pl) & 310 & 77.8 & 62.2 & 247 & 0.55 \\
\hline
\end{tabular}

Durability of mortars, after 28 days of curing, was determined by exposing them to impact of the test environment (distilled $\mathrm{H}_{2} \mathrm{O}$ ) and aggressive environment, i.e.: 1,3 and $5 \%$ hydrochloric acid solution $(\mathrm{HCl})$ for a period of 52 weeks. In order to compare obtained results of compressive strength testing, samples were stored in lab conditions, in water of constant temperature $20 \pm 2^{\circ} \mathrm{C}$ for the entire time of testing (up to 365 days). All samples were prepeard and compressive strength tests were proceeded according to PN-EN 196-1:2016-07 
[21]. Linear changes were determined in a Graff-Kauffman apparatus acc. to requirements of PN-B-19707:2013. An expansion value (Xt) was expressed as a difference of an arithmetic mean value of length changes of specimen stored in the corrosive and test environment (in distilled water) for the given exposure time ( $\mathrm{t}$ ), in \%. In addition, changes of mass (mass loss and gain) were tested in those mortars, depending on a type of environment acting on mortars. At the same time the visual observation was conducted of changes occurring on the mortar surface, illustrated by photographic documentation. Tests of compressive strength, linear and mass changes, were performed on mortar samples of dimensions 40x40x160 mm.

Porosity testing of mortars cured for 365 days in distilled water and $1 \%$ hydrochloric acid solution, was conducted by means of a mercury porosimeter - PoreMaster 60. Samples were tested in a low and high-pressure chamber exposing them to the pressure of : $1.5-350 \mathrm{kPa}$ and $420 \mathrm{MPa}$ respectively.

\section{Test results}

\subsection{Determination of mortars consistency}

Obtained test results of mortars consistency (Fig. 1, Table 2) indicate that the addition of fly ashes from fluidized bed boilers - $\mathrm{P}_{\mathrm{f}}$ and conventional boilers - $\mathrm{P}_{1}$ to the cement and their quality has the influence on cement water demand And thus: addition of 45 mass \% of FBC fly ashes to cement in ZIV mortar required the use of highest water quantity $(\mathrm{w} / \mathrm{b}=0.61)$, in order to obtain standard mortar consistency (cone penetration value equal to $5 \pm 0.5 \mathrm{~cm}$ ).

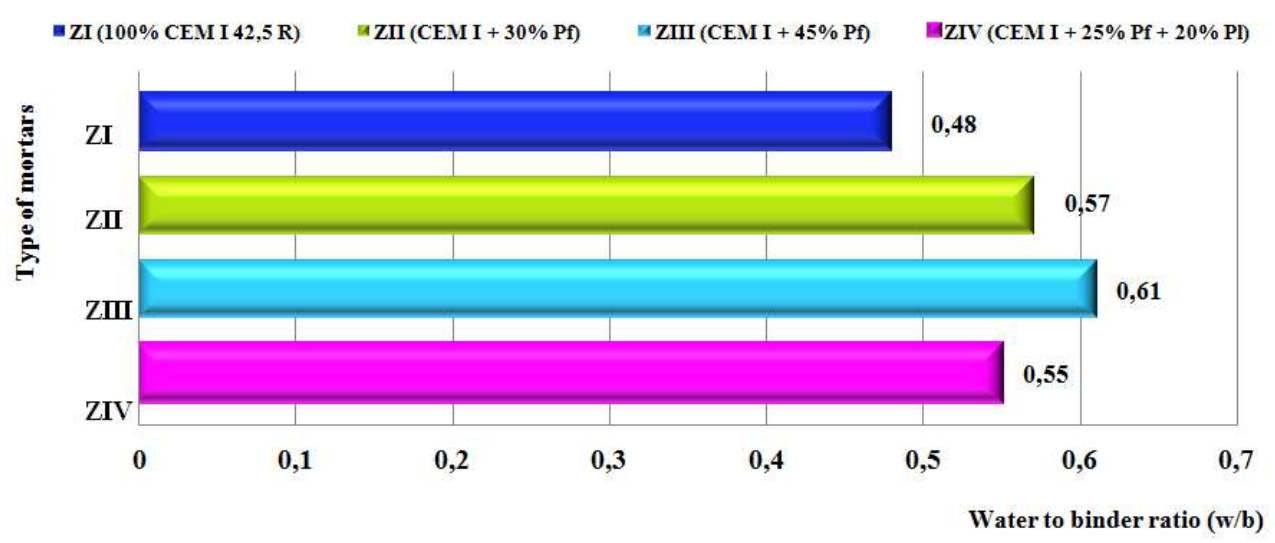

Fig 1. The amount of water needed to obtain standard mortar consistency for mortars with cement CEM I 42,5 R with and without addition of FBC and conventional fly ashes

Whereas reduction of $\mathrm{FBC}$ ashes in cement from $45 \%$ to $30 \%$ by mass, caused smaller water demand in case of ZII mortar $(\mathrm{w} / \mathrm{b}=0.57)$. On the other hand, by replacing $20 \mathrm{mass} \%$ of FBC fly ashes with conventional fly ashes, allowed for the highest reduction of water in case of ZIV mortar containing a mix of 25 mass $\%$ of $P_{f}$ fly ashes and 20 mass $\%$ of $P_{1}$ fly ashes $(\mathrm{w} / \mathrm{b}=0.55)$.

The above results show that application of fly ashes from fluidized bed combustion to the cement leads to increased water demand of the binder. Analogical conclusions can be also found in works [8] and [22]. 


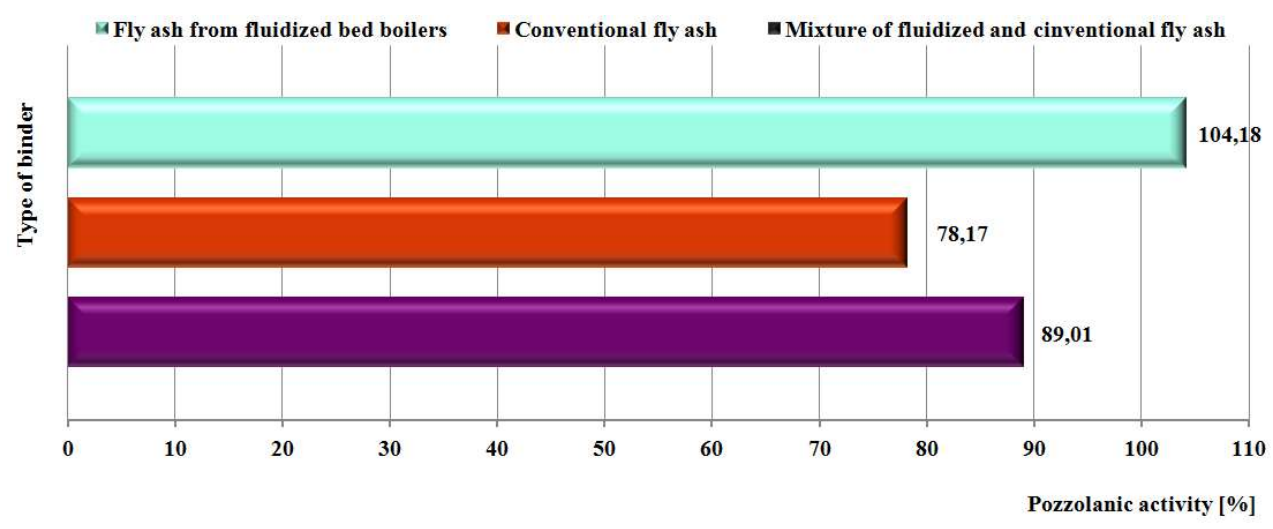

Fig. 2. The pozzolanic activity of FBC and conventional fly ashes acc. to PN-EN 450-1:2012

The analysis of pozzolanic activity test results for FBC and conventional fly ashes used separately in amount of $25 \%$ of binder mass and in a form of a mixture $\left(\mathrm{P}_{\mathrm{f}}=12.5 \%\right.$ and $\mathrm{P}_{1}=12.5 \%$ of binder mass) demonstrated that FBC fly ashes showed the highest pozzolanic activity (104.2\%, Fig. 2). The pozzolanic activity lower by $26 \%$ was demonstrated by conventional fly ashes, and in their case the pozzolanic activity index was $78.2 \%$. On the other hand, a mix of FBC and conventional fly ashes demonstrated an intermediate pozzolanic activity index, i.e. $89 \%$. All mortars tested reach the minimum pozzolanic activity index (75\%) specified by PN-EN 450-1: 2012.

\subsection{Determination of compressive strength}

Based on compressive strength test results (Fig. 3-6) it was found that introduction of a lower (30 mass\%) and higher (45 mass\%) quantity of FBC fly ashes to the cement (in mortars: ZII and ZIII respectively) and a mixture containing 25 mass\% of FBC fly ashes and 20 mass \% of conventional fly ashes in ZIV mortar, led to their decreased compressive strength in the period till 28th day of curing, compared to compressive strength of the test mortar of cement type CEM I 42,5R (ZI). The strength of ZII mortar containing 30 mass\% of FBC fly ashes was $49.4 \mathrm{MPa}$ and it was by $17 \%$ lower than the compressive strength of ZI test mortar. Whereas in case of ZIII mortar with 45 mass \% of FBC fly ashes content, the compressive strength was $41.9 \mathrm{MPa}$ and was by $30 \%$ lower than for ZI mortar. The lowest compressive strength value (40.7 MPa) was obtained by ZIV made of 25 mass $\%$ of FBC fly ashes and 20 mass $\%$ of conventional fly ashes, which was by $32 \%$ lower from the compressive strength from the cement mortar (ZI) - without fly ashes content.

After 28 days of curing in tap water, mortars were exposed to impact of various environments, including the test environment (distilled water) and aggressive solutions of $\mathrm{HCl}$ for the period of 365 days. The analysis of results of compressive strength tests for mortars stored in distilled water for 365 days (Fig. 3) showed that mortars based on pure cement CEM I 42,5R demonstrate the growth in strength in the entire curing period (from $1 \mathrm{st}$ till 365th day of testing) reaching the compressive strength equal to $63.6 \mathrm{MPa}$ after 365 days. The strength gain by $27 \%$ was observed also in case of the mortar containing a mix of FBC fly ashes ( $25 \%$ by mass) and conventional fly ashes ( $20 \%$ by mass), where after 365 days of testing, the strength was $51.8 \mathrm{MPa}$. Whereas mortars with FCB fly ashes used in quantity 30 mass\% (ZII) and 45 mass\% (ZIII) showed the increase of compressive strength of ca. $18 \%$ up to 90 th day of testing, and after that period their compressive strength reduction was observed at the level of ca. 6-8\%. It shall be emphasized that despite strength reduction between 90th and 365th day of testing, mortars ZII and ZIII subject to aggressive 
environment impact for 365 days, achieved higher compressive strength values compared to their initial values, which they had after 28 days of curing in tap water.

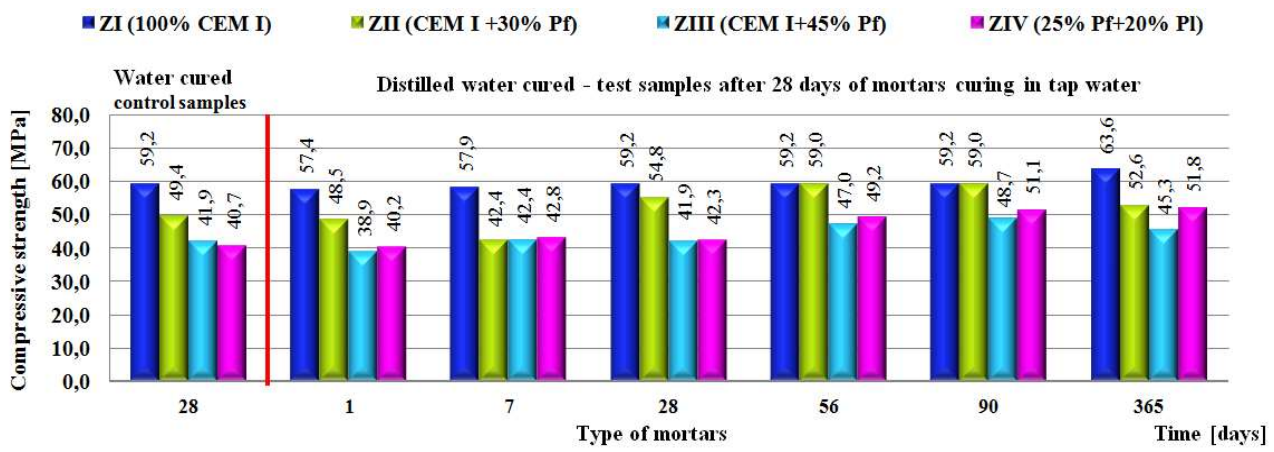

Fig 3. Compressive strength of mortars from CEM I 42,5R cement with fly ashes from fluidized bed combustion and conventional boilers cured in water for the entire period of testing ( 28 days +365 days)

On the other hand observation of mortars resistance to corrosive environment of $1 \%$ hydrochloric acid (Fig. 4) demonstrated that from 90th till 365th day of testing, the strength of mortars with addition of $30 \%$ FBC fly ashes stayed at the similar level to the strength of ZI test mortar based on CEM I 42,5R. In case of mortars with higher content (45 mass\%) of FBC fly ashes (in ZIII mortar), as well as the mixture of ashes ( 25 mass $\%$ of $\mathrm{P}_{\mathrm{f}}$ and 20 mass $\%$ of $\mathrm{P}_{1}$ in ZIV mortar) the strength value is similar and practically stays on the same level for the entire period of aggressive environment impact (up to 365 days). A slight drop of the strength by just $9 \%$ was observed in case of ZIV mortar, and by $15 \%$ in case of ZIII mortar in the time period from 90 th and 365 th day of testing.

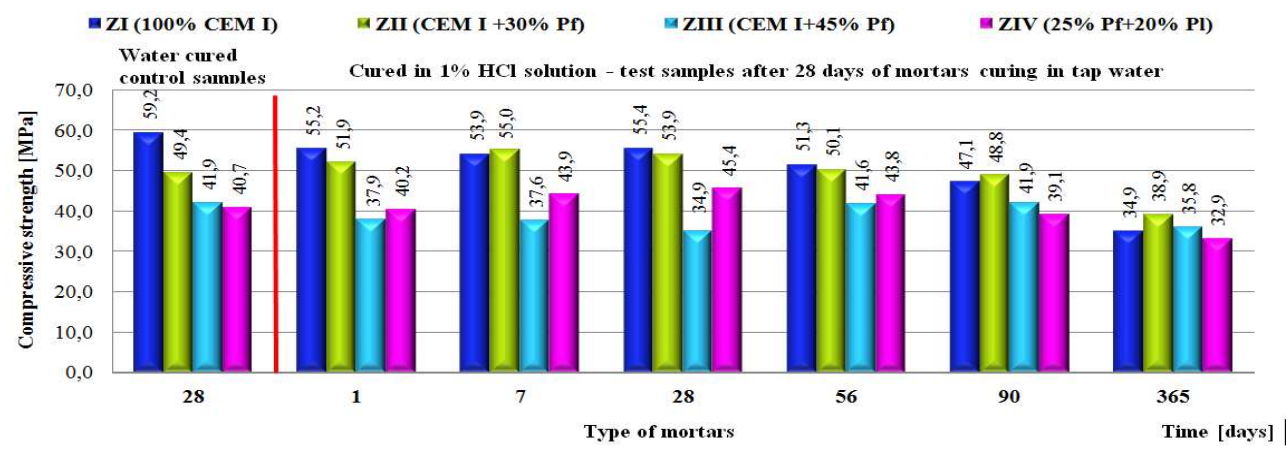

Fig. 4. Compressive strength of mortars from CEM I 42,5R cement with fly ashes from fluidized bed combustion and conventional boilers cured in water for a period of 28 days. After that period, samples were transferred to $1 \% \mathrm{r}-\mathrm{r} \mathrm{HCl}$ and the compressive strength was tested after 1, 7, 28, 56, 90 and 365 days.

Increase of aggressiveness of hydrochloric acid environment up to 3\% caused reduction of the compressive strength (Fig. 5) in case of all mortars tested (regardless of their composition), which was respectively: $69 \%$ in ZI mortar, $60 \%$ in ZII mortar, $55 \%$ in ZIII mortar and $65 \%$ in ZIV mortar compared to the strength of these mortars before the start of aggressive environments impact testing (after 28 days of mortars curing in water ). 


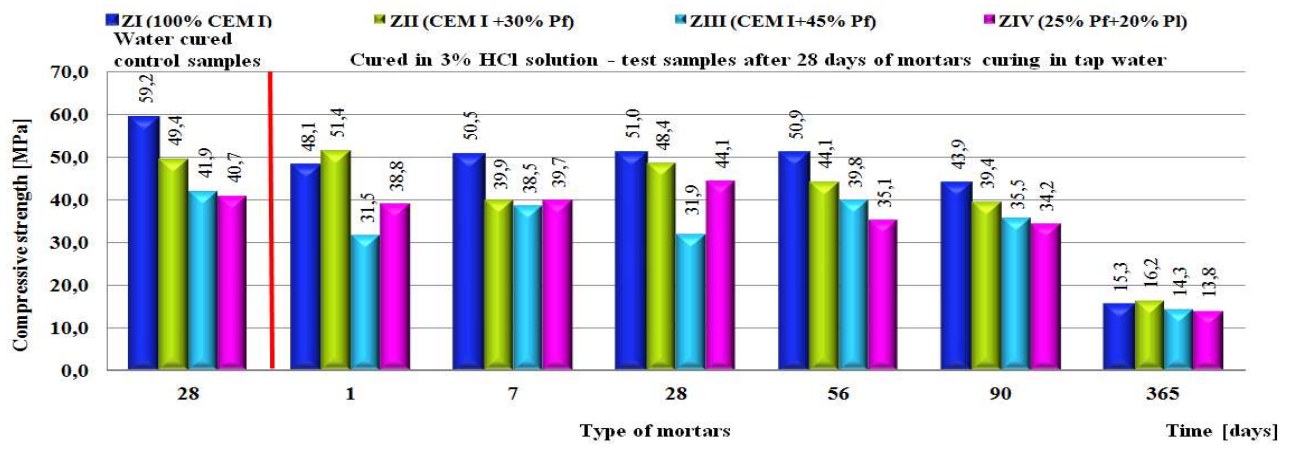

Fig. 5. Compressive strength of mortars from CEM I 42,5R cement with fly ashes from fluidized bed combustion and conventional boilers cured in water for a period of 28 days. After that period, samples were transferred to $3 \% \mathrm{HCl}$ solution and the compressive strength was tested after $1,7,28,56$, 90 and 365 days.

It was demonstrated that the compressive strength of mortars: cement and ash mortar in $5 \%$ solution of hydrochloric acid (Fig. 6) dropped rapidly and the lower it was, the shorter the time of the solution with the highest chemical aggressiveness impact was.

ZII mortar, despite high initial strength gain $(54,4 \mathrm{MPa})$, after 365 days of $5 \% \mathrm{HCl}$ impact, shows comparable strength values as remaining mortars (ca. 1.2 MPa). The compressive strength drop for this mortar is the highest and already after 56 days of testing it reaches $40 \%$. Whereas the lowest drop of the compressive strength in the entire period of tests was showed by ZIV mortar stored in $5 \% \mathrm{HCl}$ solution.

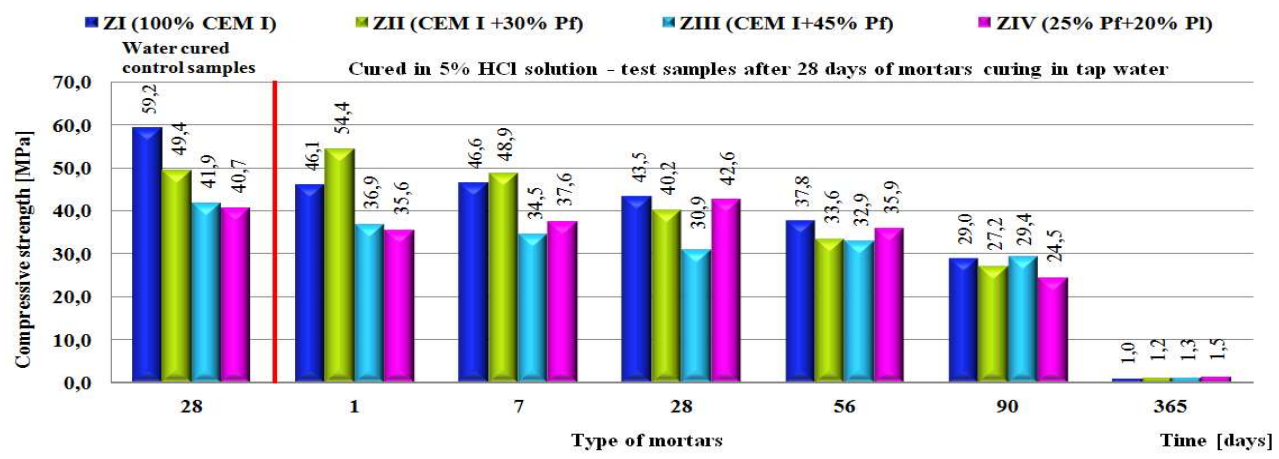

Fig. 6. Compressive strength of mortars from CEM I 42,5R cement with fly ashes from fluidized bed combustion and conventional boilers cured in water for a period of 28 days. After that period, samples were transferred to $5 \% \mathrm{HCl}$ solution and the compressive strength was tested after 1, 7, 28, 56, 90 and 365 days.

\subsection{Linear and mass changes of mortars subject to impact of various environments}

Relation of linear changes from mass changes (loss or gain) for mortars without and with the content of fly ashes from fluidized bed boilers and conventional boilers, subject to impact of various environments (distilled $\mathrm{H}_{2} \mathrm{O}$ and 1,3 and $5 \%$ solutions of $\mathrm{HCl}$ ) in time from 1 to 365 days of testing is presented in Figures 7a-d.

Linear and mass changes of mortars with fly ash from fluidized bed boilers and with the mixture of ashes from fluidized and conventional combustion : 

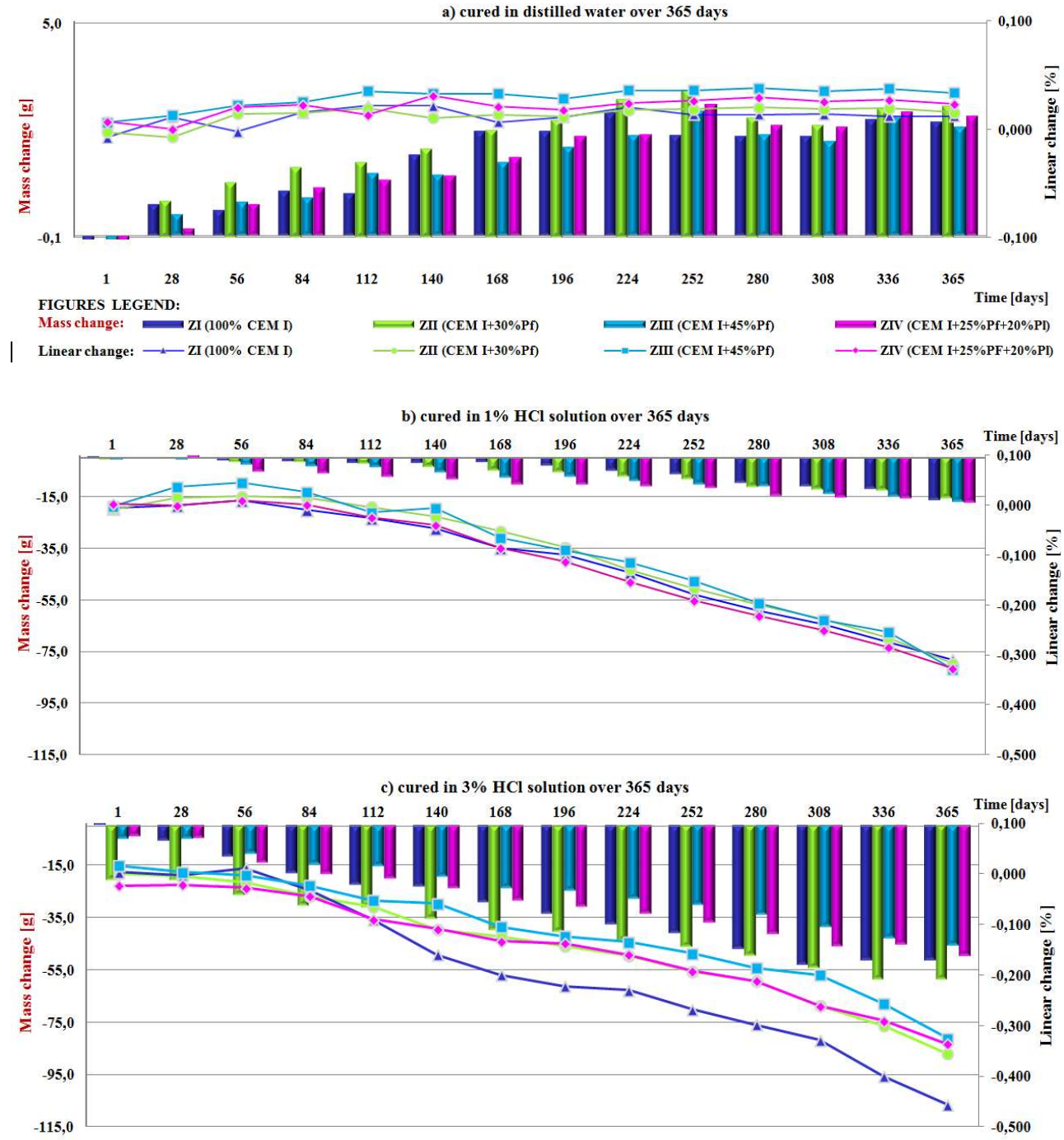

d) cured in 5\% $\mathrm{HCl}$ solution over 365 days

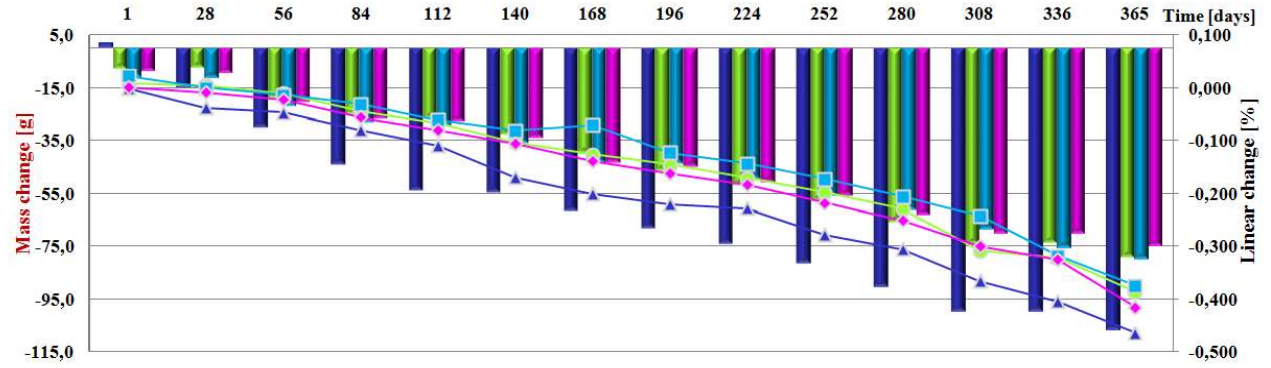

Fig. 7. Linear and mass changes of mortars of CEM I 42,5R cement without and with the content of fly ashes from fluidized bed boilers ( $\mathrm{Pf}$ ) and conventional boilers (P1) in environment: a) $\left.\mathrm{H}_{2} \mathrm{O}, \mathrm{b}\right) 1 \% \mathrm{HCl}$ solution, c) $3 \% \mathrm{HCl}$ solution, d) $5 \% \mathrm{HCl}$ solution [23] 
Obtained results of linear changes tests (Fig. 7a-d), indicate destructive impact of acid corrosion environment on durability of mortars tested, depending on their composition. The above relation was also confirmed by results of mortars mass changes tests (Fig. 7a-d). It shall be noted that in the test environment $\left(\mathrm{H}_{2} \mathrm{O}\right)$ the mortars elongation phenomenon was characteristic, which is also confirmed by mass gain test results (Fig. 7a), whereas in the corrosive environment, the mortar dimension reduction was observed and the mass loss, which increased as the environment aggressiveness grew (Fig. 7b-c).

In $1 \% \mathrm{HCl}$ solution, linear changes were observed at the comparable level regardless of composition of mortars (Fig. 7b). Increase of $\mathrm{HCl}$ solution concentration to $3 \%$ (Fig. 7c) showed clear differences in linear changes and mass loss of mortars, where the highest reduction of dimensions and mass loss was demonstrated by ZII mortar containing 30 mass $\%$ of FBC fly ashes, and the lowest by: ZIII mortar with z 45 mass $\%$ content of these ashes (Pf) and ZIV mortars containing a mixture of 45 mass $\%$ fly ashes $(25$ mass $\%$ of Pf and 20 mass $\%$ of $\mathrm{Pl}$ ). The most aggressive environment of $5 \% \mathrm{HCl}$ solution had the highest impact on dimension reduction and the highest mass loss in case of the reference mortar from the same cement, i.e. CEM I 42.5 R. In these conditions, the lowest linear changes were demonstrated by ZIII mortar with 45 mass\% of FBC fly ashes (Fig. 7d). It can be assumed that that mortar in general demonstrated the lowest mass loss, regardless on aggressiveness of the acid environment $(1 \%, 3 \%$ and $5 \% \mathrm{HCl}$, Fig. $7 \mathrm{~b}-7 \mathrm{~d})$. On the other hand $\mathrm{ZIV}$ mortar containing a mixture of 25 mass \% of FBC fly ashes and 20 mass \% of ashes from conventional boilers in $5 \% \mathrm{HCl}$ solution, in the final period of testing (after 336 days of testing), showed a slightly lower mass loss compared to ZII mortar (Fig. 7d).

The highest dimension in cross-section obtained by ZIII mortar confirmed that the mortar of CEM I 42,5R cement with 45 mass\% of FBC fly ashes showed the highest resistance to aggressive environment, both in $3 \%$ and $5 \% \mathrm{HCl}$ solution.

Whereas the content of $30 \%$ by mass of FBC ashes in ZII mortar carries a higher risk of destruction and less resistance of this mortar to acid corrosion $(3 \%$ and $5 \% \mathrm{HCl})$, which is also demonstrated by a smaller core cross-section of the mortar not affected with the corrosion (Fig.8 - 9).

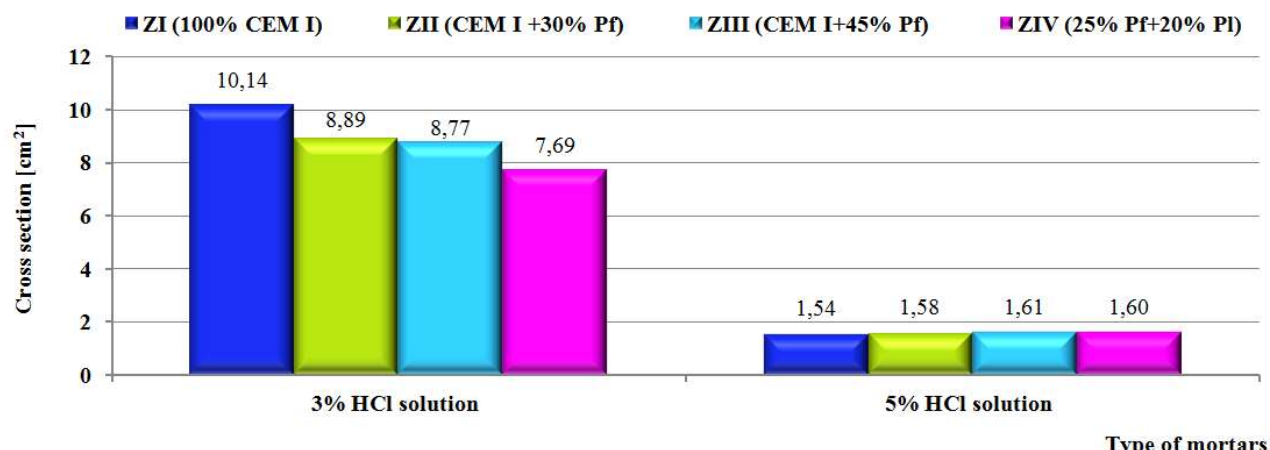

Fig. 8. Cross-section dimensions of cement based mortars, without content of $F B C$ and conventional fly ashes cured in water for 28 days, and then subject to impact of corrosive environments ( $3 \%$ and $5 \%$ of hydrochloric acid solution) for the period of 365 days

In $5 \% \mathrm{HCl}$ solution environment, as could be expected, the core cross-section size for the test mortar of pure CEM I 42,5R (without content of fly ashes) was the smallest, which is in line with the previous results regarding the lowest linear changes and the highest mass loss for this mortar (ZI, Fig. 7d). 


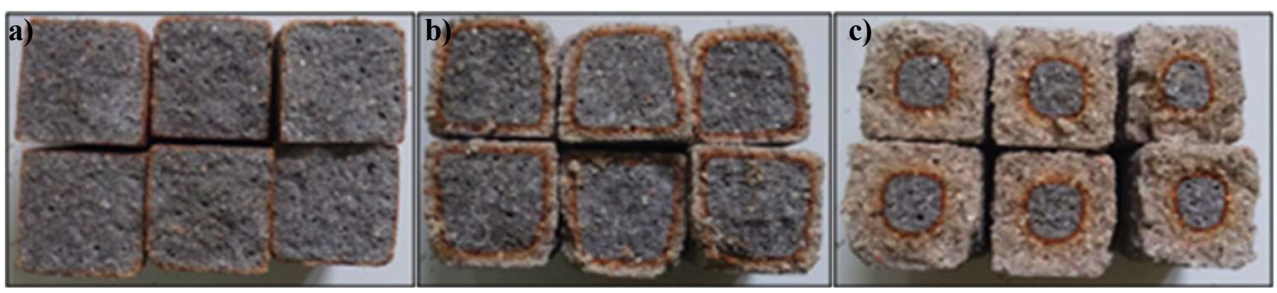

Fig. 9. Internal structure of mortar ZIV with CEMI $+45 \%$ Pf after 365 days in a) $1 \% \mathrm{HCl}$ solutions, b) $3 \% \mathrm{HCl}$ solutions and c) in $5 \%$ hydrochloric acid solution

\subsection{Testing of porosity}

Porosity of mortars has a very large impact on their resistance to the impact of aggressive environment. Migration of aggressive ions proceeds with the increase of capillary pores content $(0.09-15 \mu \mathrm{m})$ [17]. Destruction of mortars caused by impact of 3 and $5 \%$ hydrochloric acid solution was so large that it prevented porosity testing for samples kept in those environments. Fig. 10-11 shows differential curves of pores distribution for all mortars cured in water and in $1 \%$ of hydrochloric acid solution.

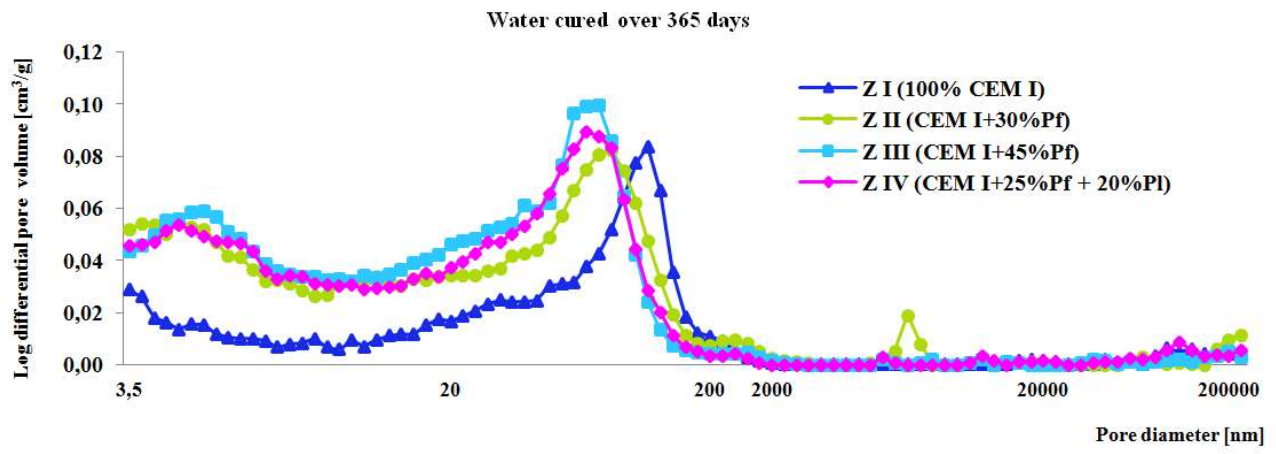

Fig. 10. The differential curve of pores volume distribution as a function of their diameter in mortar samples kept in water for $28+365$ days,

Cured in $1 \%$ HCl solution over 365 days

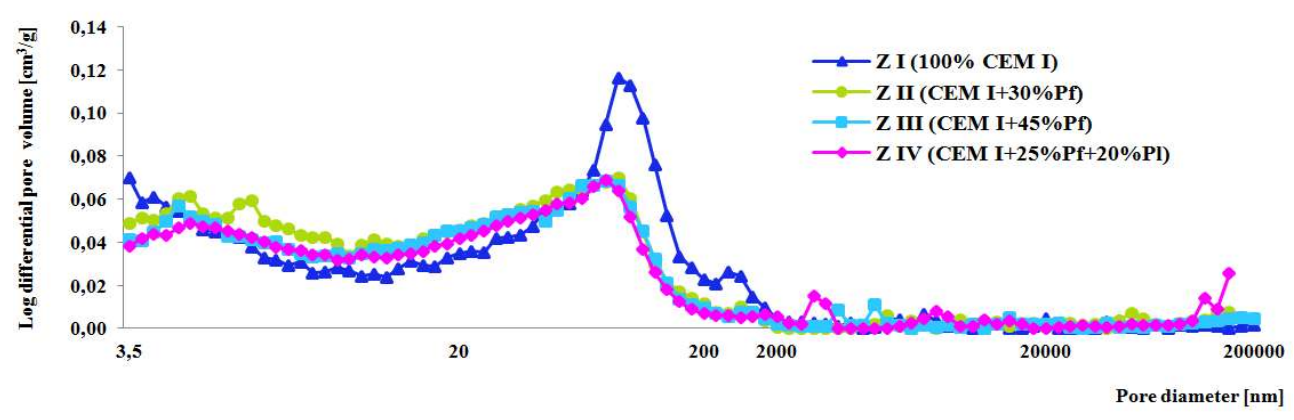

Fig. 11. The differential curve of pores volume distribution as a function of their diameter in mortar samples kept in water for 28 days. After that period samples were transferred to $1 \% \mathrm{HCl}$ solution for the period of 365 days.

Total porosity and percentage distribution of pores are shown in Table 3. Obtained results of tests indicate a higher total porosity equal to $17 \%$ in case of mortars with the highest 45 
mass\% content of FBC fly ashes (ZIII) compared to porosity of mortars containing their lowest content (30 mass\% in ZII) or the mix of FBC and conventional ashes in ZIV mortar. The total content of pores in the cement mortar (ZI) was the lowest and amounted to $11.4 \%$, higher in the mortar with 30 mass\% contend of FBC fly ashes (ZII) - 16.7\%. Whereas the mortar containing a mixture of 25 mass $\%$ of FBC fly ashes and $20 \%$ of conventional fly ashes (ZIV) showed a slightly lower total porosity equal to $16.3 \%$. It is interesting that despite higher total porosity in cement and ash mortars, the content of pore size from $20-200 \mathrm{~nm}$ is lower than in the cement mortar (Table 3).

Total quantity of pores for the mortar of pure cement (ZI) cured in $1 \% \mathrm{HCl}$ solution is two times higher compared to porosity of samples of this mortar kept in distilled water, and it is $22.6 \%$. Also in case of ZII mortar with $30 \%$ content of FBC fly ashes, the total content of pores increased by a few percent. On the other hand, increase of fly ashes content in the cement with $30 \%$ (ZII) to 45 mass \% (ZIII) had no significant impact on the increase of the total porosity, regardless of test environment $\left(\mathrm{H}_{2} \mathrm{O}\right.$ and $\left.1 \% \mathrm{HCl}\right)$. Application of fly ashes in composition of mortars, such as samples cured in distilled water, and in this case it resulted in reduction in content of pores size 20-200 nm with simultaneous increased content of pores $<20 \mathrm{~nm}$ (Fig. 11).

Table 3. Percentage content of pores in mortars cured for 365 days in water and $1 \% \mathrm{HCl}$ solution

\begin{tabular}{|c|c|c|c|c|c|c|c|c|}
\hline \multirow[b]{2}{*}{ Sample type } & \multirow{2}{*}{$\begin{array}{c}\text { Apparen } \\
\text { t density } \\
\text { g/ } \mathbf{c m}^{3}\end{array}$} & \multirow{2}{*}{$\begin{array}{c}\text { Total } \\
\text { porosity } \\
{[\%]}\end{array}$} & \multicolumn{6}{|c|}{ Percentage of pores [\%] } \\
\hline & & & $<20 \mathrm{~nm}$ & $<50 \mathrm{~nm}$ & $\begin{array}{c}20-200 \\
\mathrm{~nm}\end{array}$ & $\begin{array}{c}200- \\
2000 \\
\text { nm }\end{array}$ & $\begin{array}{c}2000- \\
20000 \\
\text { nm }\end{array}$ & $\begin{array}{c}<\mathbf{2 0 0 0 0} \\
\mathbf{n m}\end{array}$ \\
\hline \multicolumn{9}{|c|}{$\mathrm{H}_{2} \mathrm{O}$} \\
\hline Z I (100\% CEM I) & 2.12 & 11.4 & 17.7 & 36.9 & 68.3 & 7.7 & 0.4 & 5.4 \\
\hline Z II (CEM I + 30\% Pf) & 2.10 & 16.7 & 36.3 & 59.5 & 49.2 & 7.7 & 2.2 & 4.6 \\
\hline Z III (CEM I + 45\%Pf) & 2.07 & 17.0 & 38.3 & 67.5 & 53.5 & 4.7 & 0.9 & 2.6 \\
\hline Z IV $($ CEM I + 25\% Pf + 20\%Pl) & 2.11 & 16.3 & 37.3 & 66.6 & 54.1 & 3.3 & 0.6 & 4.6 \\
\hline \multicolumn{9}{|c|}{$1 \%$ HCl solution } \\
\hline Z I (100\% CEM I) & 2.15 & 22.6 & 26.4 & 44.3 & 53.6 & 15.8 & 2.5 & 1.3 \\
\hline Z II (CEM I + 30\% Pf) & 2.10 & 19.7 & 37.1 & 60.1 & 47.3 & 8.9 & 1.8 & 4.6 \\
\hline Z III (CEM I + 45\%Pf) & 2.08 & 16.8 & 37.9 & 63.9 & 49.0 & 7.0 & 2.5 & 3.6 \\
\hline Z IV (CEM I + 25\% Pf $+20 \% \mathrm{Pl})$ & 2.09 & 17.1 & 35.6 & 60.3 & 46.2 & 7.1 & 4.2 & 6.7 \\
\hline
\end{tabular}

It has been demonstrated that with the rise of macropores $(<50 \mathrm{~nm})$ content, the compressive strength of mortars increases, which in water environment is more visible for the cement based mortar, whereas in the acid aggressiveness environment this relation is more favourable in case of ash mortars containing higher amount of fly ashes from fluidized bed combustion (Table 3, Fig. 4). The above results of tests are in line with results of works [4].

\section{Conclusions}

Results of tests of mortars consistency demonstrated that the addition of FBC fly ashes increased the water demand of cement, while substituting FBC fly ashes with 20 mass\% of conventional fly ashes had the impact on $10 \%$ reduction of the cement water demand, which was confirmed by a reduced w/b value from 0.61 for ZIII mortar to 0.55 for ZIV mortar.

Addition of 45 mass $\%$ of FBC fly ashes to the cement appeared to be optimum, compared to a lower value $(30$ mass $\%$ content of those ashes or applied mixture of 20 mass $\%$ of 
conventional fly ashes and 25 mass $\%$ of FBC fly ashes. The above confirmed high compressive strength values at a quite balanced level, and the lowest impact of aggressive environment (1, 3 and $5 \% \mathrm{HCl}$ solutions) on destruction of ZIV mortar, demonstrated by the smallest linear changes and the lowest mass loss. At the same time it was demonstrated that in the environment of aggressive hydrochloric acid solution $(1 \% \mathrm{HCl})$, the content of macropores $(<50 \mathrm{~nm})$ was higher than in case of mortars containing FBC fly ashes compared to mortars based on pure Portland cement CEM I, which justified higher compressive strength values of mortars with ash content. An opposite relation was observed in the water environment, where the content of macropores was higher for the cement mortar, which also translated also its higher compressive strength. The above results from a hydratation process of binders, which for pure cement in water environment is distinguished by higher formation of C-S-H phase, having a direct impact on the strength gain. Presence of fly ashes showing pozzolanic properties leads to formation of hydrated calcium silicates delayed in time, presence of which in the acid aggressive environment in mortars of fly ashes, protects the mortar against a destructive impact of acid solution due to lower quantity of portlandite formed -the least resistance to corrosive conditions.

The explanation of the destructive impact of acid corrosion environment on durability of cement mortars is the reaction of the acid with cement stone, in result of which the calcium hydroxide $\mathrm{Ca}(\mathrm{OH})_{2}$ is dissolved and easy soluble calcium salts $\left(\mathrm{Ca}_{n} \mathrm{R}\right)_{2}$ are formed, rinsing out of which weakens a mortar microstructure [19]. In consequence, in a large generalization, it leads to decalcification of the paste, which is connected with reduced quantity of portlandite and decalcification of C-S-H phase. Then the C-S-H phase, impoverished with $\mathrm{Ca}^{2+}$ ions, reacts with acid and in result the calcium salt is formed $\left(\mathrm{Ca}_{n} R_{2}\right)$ and the amorphic silica gel $\left(n y S i(O H)_{4}\right)$, which has no binding and strength properties.

Also ettringite and aluminate monosulphates are dissolved. The above leads to reduction of mortar durability [17-20].

Furthermore, the impact of acid environment was also visible on reduction of aggregate grain adhesion to the paste, caused by flushing out of its constituents, which was observed in case of mortars with addition of fly ashes (ZII, ZIII and ZIV) subject to impact of aggressive hydrochloric acid environment of a lower $\mathrm{pH}$ reaction $(3-5 \% \mathrm{HCl})$.

As shown by results of this study, application of fly ashes from fluidized bed boilers as an ingredient of mortars, may lead to stop their destruction in the acid aggressiveness environment. It may be explained by increased contribution of $\mathrm{C}-\mathrm{S}-\mathrm{H}$ phase coming from hydratation of ashes that show both pozzolanic and hydraulic properties. It was demonstrated that resistance of mortars to acid corrosion increased along with the higher content of ashes from fluidized bed combustion in the cement.

\section{References}

1. Energy policies of IEA Countries- Poland - 2016 review, 73

2. R. Bartnik, Problems facing the Polish power engineering, Conference - „XVII Innowacje w Zarządzaniu i Inżynierii Produkcji”, 379-391 (2014)

3. J. Niesler, Development of fluidised bed furnaces in the power industry, PPIK, 4, 33-36 (2011)

4. A. M. Brandt (Ed.) Application of CFBC fly ash in structural concretes (IPPT, 2010)

5. R. E. Conn, K. Sellakumar, Utilization of CFB fly ash for construction applications, Proceedings of the 15th International Conference on Fluidized Bed Combustion, (1999)

6. M. Gawlicki, W. Roszczynialski, Fluidized bed combustion by-products - evaluation of potential use in cement industry, MATBUD'2003 , 25-27 ( 2003) 
7. J. Brandstetr, J. Havlica, I. Odler, Properties and use of solid residue from fluidized bed coal combustion. Waste Materials Used in Concrete Manufacturing, (Noyers Publications, 1997)

8. S. Grzeszczyk, E. Janowska-Renkas, J. Kowalska, Rheological properties of fluidized bed boilers fly ash, Annuals of Civil Engineering, 13, 63-66 (2013)

9. K. Rajczyk. Fly ash from fluidized bed boilers and the possibilities of their refinement (WYDIS, 2012)

10. H. Maenami, N. Isu, E. Ishida, T. Mitsuda, Electron microscopy and phase analysis offly ash from pressurized fluidized bed combustion, Cem. Concr. Res. 34, 781-788 (2004)

11. W. Zhang, H. Choi, T. Sagawa, Y. Hama, Compressive strength development and durability of an environmental load-reduction material manufactured using circulating fluidized bed ash and blast-furnace slag, Const. Build. Mater. 147, 102-113 (2017)

12. P. Chindaprasirt, U. Rattanasak, C. Jaturapitakkul, Utilization of fly ash blends from pulverized coal and fluidized bed combustions in geopolymeric materials, Cem. Concr. Comp. 33, 55-60 (2011)

13. V. Zivica, A. Bajza, Acidic attack of cement based materials - a review. Part 1 . Principle of acidic attack, Constr. Build. Mater. 331-340 (2001)

14. A. Łagosz, J. Małolepszy, J. Śliwiński, T. Tracz, Fly ash from fluidized bed combustion as a mineral addition to concrete, Conference - „Dni Betonu”, 553-566 (2008)

15. PN-EN 197-1:2012 Cement- Part 1: Composition, specifications and conformity criteria for common cements

16. PN-EN 450-2012 Fly ash for concrete - Part 1: Definition, specifications and conformity criteria

17. W. Kurdowski, Cement and Concrete Chemistry, ( PWN, 2010)

18. B. Słomka-Słupik, A. Zybura, Experimental research of cement paste decalcification, Conference - „Dni Betonu”, 787-796 (2010)

19. J. Małolepszy, R. Mróz, The influence of sulphate corrosion on durability of cement mortars produced from cements containing bottom-ashes, Conference - „VII Sympozjum Naukowo -Techniczne Reologia w Technologii Betonu”, 17-28 (2005)

20. M. J. Łączny, G. Majka, M. Cempa-Balewicz, Study on the impact of fluidized bed ash processed by carbonation on mechanical properties of cement mortar, Cem. Wapno Beton, 4, 265-273 (2016)

21. PN-EN-196-1:2016-07 Methods of testing cement- Part 1: Determination of strength

22. Z. Pytel, Properties of cements containing ashes from fluidised bed combustion installations, Conference - „Dni Betonu”, 476-477 (2002)

23. E. Janowska-Renkas, J. Kowalska, A. Kaliciak, G. Janus, The resistance of mortars with fluidized beds boiler fly ashes and conventional fly ashes to acid corrosion, Annuals of Civil Engineering, 16, 101-109 (2016) 